\title{
Intumescent Coatings Based on Tannins for Fire Protection
}

\author{
Mauro Ricardo da Silveira ${ }^{a} \mathbb{D}^{\mathbb{D}}$, Rafael Silveira Peres ${ }^{a}$, Vicente Fróes Moritz ${ }^{a}$, Carlos Arthur Ferreira
}

\author{
${ }^{a}$ Laboratório de Materiais Poliméricos - LAPOL, Programa de Pós-Graduação em Engenharia de \\ Minas, Metalúrgicae de Materiais - PPGE3M, Universidade Federal do Rio Grande do Sul, Av. Bento \\ Gonçalves, 9500, 91501-970, Porto Alegre, RS, Brasil
}

Received: June 20, 2018; Revised: October 24, 2018; Accepted: January 17, 2019

\begin{abstract}
Accidents involving fire occur every day around the world, affecting thousands of people and causing economic losses. Some accidents are caused by steel structure failures, which experience a significant reduction in mechanical properties at temperatures of $400-550^{\circ} \mathrm{C}$. Therefore, fire protective coatings are required for steel structures and interest in the development of intumescent coatings has increased considerably. In this study, black wattle tannin was used as a carbon source in the formulation of intumescent coatings. Concentrations of $5 \%$ and $10 \%$ of tannin were incorporated into a novolac resin. The coating was applied on a steel plate and the thermal protection was evaluated by sample exposure to a flame for $30 \mathrm{~min}$. The results showed that the tannin compound could be used as a carbon source for intumescent coatings. The temperature of the samples containing $10 \%$ of this compound was almost $300{ }^{\circ} \mathrm{C}$ lower compared to the uncoated steel plate.
\end{abstract}

Keywords: Intumescent coating, black wattle tannin, fire protection.

\section{Introduction}

The protection of wood and steel structures against fire can save many lives in cases of disaster. The escape time within a confined space can be drastically reduced during a fire because steel structures experience a significant reduction in mechanical properties at temperatures higher than $450{ }^{\circ} \mathrm{C}^{1,2}$. Thus, the use of intumescent coatings is gaining interest as an approach to protecting these structures against fire ${ }^{3-5}$.

According to Alongi et al. ${ }^{5}$, the word "intumescent" refers to a material capable of expanding under certain conditions. Thus, intumescent coatings have the ability to expand when heated during a fire, creating a barrier to heat transfer and avoiding overheating of the substrate ${ }^{6,7}$. The composition of the intumescent system is described in detail in several reviews ${ }^{5,8}$, but in general it consists of three components: an inorganic acid source, an expanding or blowing agent and a carbon source ${ }^{9}$. The acid source is responsible for dehydrating the carbon source, which leads to the formation of char by the carbon source agent ${ }^{9}$. The expanding or blowing agent decomposes and releases non-flammable gases that are responsible for expanding the coating layer ${ }^{9}$. The carbon source typically has a substantial number of carbons and hydroxyl groups to enable the esterification reaction ${ }^{7,9}$. In this regard, renewable materials, such as tannin and lignin, can be useful as the carbon source in intumescent coatings.

Tannins are polyphenolic materials that are obtained from the bark, seeds and other parts of numerous species of trees ${ }^{10,11}$. Tannins are classified in two classes: condensed and hydrolysable ${ }^{10,11}$. Condensed tannins consist of chains of polyhydroxyflavan-3-ol units and are able to complex

*e-mail: mauro.ricardo@ufrgs.br. with metals, proteins and carbohydrates ${ }^{12}$. Hydrolysable tannins are polyesters based on gallic acid, with gallotannin and ellagitannin among the classes ${ }^{11,13}$. The potential of tannin usage is very wide, including medical ${ }^{14,15}$, pharmaceutical ${ }^{16,17}$ and chemical ${ }^{18,19}$ applications, as well as the materials industry ${ }^{10,20-22}$. Our previous studies have reported the promising use of tannin as an antifouling pigment ${ }^{23,24}$ and indicated that they can be highly effective in intumescent formulations because of the presence of high amounts of aromatic carbons and hydroxyl groups.

Recently, Alongi et al. ${ }^{5}$ and Laoutid et al. ${ }^{9}$ published interesting reviews and described recent research on intumescent coatings for many applications. Natural materials are also present in intumescent formulations ${ }^{25-28}$. Yew and Sulong ${ }^{29}$ used chicken eggshell as a flame retardant filler in water-based intumescent coatings. Bodzay et al. ${ }^{30}$ reported the use of mineral clay in formulations. Sources of carbon are also the subject of investigation. Ullah et al. ${ }^{31}$ evaluated the effects of boric acid and melamine on intumescent coatings using expandable graphite as a carbon source. The presence of boric acid increased the amount of residual material on the remaining coating ${ }^{31}$. According to Gardelle et al. ${ }^{32}$, the presence of organoclay improved the mechanical properties of the char in intumescent coatings formulated with silicon. These authors also used expandable graphite as a carbon source, while Chou et al. ${ }^{33}$ used pentaerythritol. To the best of our knowledge, there are no studies showing the use of tannins as a renewable and natural carbon source in intumescent coatings in the literature.

The aim of this work is to investigate the use of black wattle tannin as a carbon source in intumescent coatings formulated with epoxy novolac resin. Several formulations were compared 
in a torch test. Complementary characterisation tests, such as X-ray diffraction (XRD) and thermogravimetric analyses (TGA), were also carried out to evaluate the oxidation of the steel substrate after the fire test and to characterise the thermal stability and determine the residual weight of the samples. These formulations allow the use of a compound of natural and renewable source that provides the formation of a carbonaceous layer rich in carbon, which acts as an insulating barrier and reduces the heat transfer from the fire to the underlying substrate.

\section{Experimental Procedure}

\subsection{Materials}

Epoxy resin novolac DEN 431 solvent-free (Dow, USA) with an epoxy equivalent weight (EEW) of about $176 \mathrm{~g} / \mathrm{eq}$ was used as a high solid binder in the intumescent coating formulation. Diethyltoluenediamine (Lonzacure ${ }^{(\mathrm{TM})} 80$ ) (Lonza, USA) with an amine hydrogen equivalent weight (AHEW) of $44.6 \mathrm{~g} / \mathrm{eq}$ was used as an epoxy novolac hardener agent. The ratio of AHEW to EEW was 0.5.

The intumescent system was prepared with organophosphorus flame retardant 9,10-dihydro-9-oxy-10-phosphaphenanthrene10-oxide (DOPO) (Tokyo Chemical Industry, Japan), triethanolamine (Sigma-Aldrich, USA), boric acid (Synth, Brazil), melamine (Sigma-Aldrich, USA) and black wattle tannin (Tanac, Brazil) as carbon sources.

\subsection{Intumescent coating formulation}

The compositions of epoxy novolac resin DEN 431 are given in Table 1 . The tannin content was $5 \mathrm{wt} \%$ for the TAN5 sample and $10 \mathrm{wt} \%$ for the TAN10 sample; the BM samples were modified with $10 \mathrm{wt} \%$ boric acid and $10 \mathrm{wt} \%$ melamine; $5 \mathrm{wt} \%$ DOPO was added to P samples. First, epoxy resin novolac DEN 431 was heated to $100{ }^{\circ} \mathrm{C}$ and stirred constantly at $300 \mathrm{rpm}$ using a mechanical stirrer model RW20 (IKA, Germany). Then, DOPO and triethanolamine were added and stirring continued at $110^{\circ} \mathrm{C}$ for $30 \mathrm{~min}$. After the reaction of DOPO and the epoxy resin, boric acid, melamine and black wattle tannin were added and the system was stirred for $30 \mathrm{~min}$ at $100^{\circ} \mathrm{C}$.

\subsection{Sample preparation}

Carbon steel substrates (AISI 1010) with dimensions of $100 \mathrm{~mm} \times 100 \mathrm{~mm} \times 0.9 \mathrm{~mm}$ were degreased with acetone and polished with \#100 sandpaper. Then, the coating samples were applied using a spatula and a mask. Perforated aluminium sheets $1.5 \mathrm{~mm}$ thick and with holes $70 \mathrm{~mm}$ in diameter were used to establish a $1.5 \mathrm{~mm}$ coating. The steel substrates and the perforated aluminium sheets were sealed with adhesive tape. The samples were cured in an oven for $1 \mathrm{~h}$ at $140{ }^{\circ} \mathrm{C}$, then the aluminium sheets were removed. The final thickness for the dry films (intumescent coatings) was $1.5 \pm 0.1 \mathrm{~mm}$, measured using a Byko-7500 thickness gauge (Byk-Gardner, Germany).

\subsection{Fire resistance test and sample characterisation}

The fire resistance test was conducted for each intumescent coating sample in triplicate. The increase in temperature after application of the flame was measured on the reverse of the metal substrate using a type $\mathrm{K}$ thermocouple (Thermomax, Brazil), as shown in Figure 1.

The temperature distribution on the reverse of the samples was carried out with a Fluke Ti400 thermography camera (Fluke, Canada) in the infrared spectral range. An acquisition module developed in the laboratory was used to perform collection of the thermocouple data. The flame was applied for $30 \mathrm{~min}$ using a Dremel model blowtorch, VersaFlame (Dremel, Germany). This butane torch reaches a maximum temperature of $1150{ }^{\circ} \mathrm{C}$.

TGA of the samples was conducted using a thermogravimetric analyser, model TGA Q50 (TA Instruments, USA). The samples (about $10 \mathrm{mg}$ ) in the form of powder were placed in an open platinum pan. TGA experiments were carried out in inert atmosphere $\left(\mathrm{N}_{2}\right)$ within the temperature range $25^{\circ} \mathrm{C}$ to $900{ }^{\circ} \mathrm{C}$ at a heating rate of $20^{\circ} \mathrm{C} / \mathrm{min}$.

$\mathrm{XRD}$ analyses were performed to investigate the change in the steel surface (reverse) after application of the flame. The XRD patterns were obtained by analysing the reverse face of the substrate. The equipment used was the X'pert MPD (Philips, Netherlands) with $\mathrm{CuK}$ radiation and a scan rate of $0.05 \%$. The test was performed on three samples: uncoated steel (blank) before the fire test, uncoated steel (blank) after the fire test and the steel plate coated with TAN10-BM-P intumescent coating after the fire test.

\section{Results and Discussion}

\subsection{Fire resistance test}

Initially, all formulations described in Table 1 were exposed to a blowtorch for $30 \mathrm{~min}$. The temperature variation was recorded and is shown in Figure 2.

For all samples, as can be seen in Figure 2, the temperature of coatings stabilised after 3-6 min of fire testing. The blank sample reached $400^{\circ} \mathrm{C}$ after $3 \mathrm{~min}$ of exposure to the flame, with the temperature increasing to values higher than $450^{\circ} \mathrm{C}$ after $10 \mathrm{~min}$ (Figure 2). As previously mentioned, in this temperature range the structural properties of steel could be impaired ${ }^{1,2}$. Similar temperatures for the uncoated substrate (blank) were also found by Ullah et al. ${ }^{31}$. The pure epoxy resin novolac reached a temperature of approximately $330{ }^{\circ} \mathrm{C}$ after $5 \mathrm{~min}$ of the exposure to the flame. This decrease in the temperature compared to the uncoated steel is due to the high thermal stability of novolac resins (high crosslinking) ${ }^{34}$. According to Wang et al. ${ }^{35}$, novolac resin 
Table 1. Composition of intumescent coatings.

\begin{tabular}{|c|c|c|c|c|c|}
\hline Sample & Novolac DEN $431(\%)^{\mathrm{a}}$ & Tannin $(\%)^{\mathrm{a}}$ & DOPO $(\%)^{\mathrm{a}}$ & Boric Acid $(\%)^{\mathrm{a}}$ & Melamine $(\%)^{\mathrm{a}}$ \\
\hline Blank (steel plate) & 0 & 0 & 0 & 0 & 0 \\
\hline Epoxy Resin & 100 & 0 & 0 & 0 & 0 \\
\hline TAN5 & 95 & 5 & 0 & 0 & 0 \\
\hline TAN5-BM & 75 & 5 & 0 & 10 & 10 \\
\hline TAN5-P & 90 & 5 & 5 & 0 & 0 \\
\hline TAN5-BM-P & 70 & 5 & 5 & 10 & 10 \\
\hline TAN10 & 90 & 10 & 0 & 0 & 0 \\
\hline TAN10-BM & 70 & 10 & 0 & 10 & 10 \\
\hline TAN10-P & 85 & 10 & 5 & 0 & 0 \\
\hline TAN10-BM-P & 65 & 10 & 5 & 10 & 10 \\
\hline
\end{tabular}

${ }^{\text {aReferring to dry mass }}$



Figure 1. Experimental scheme of the fire resistance test.

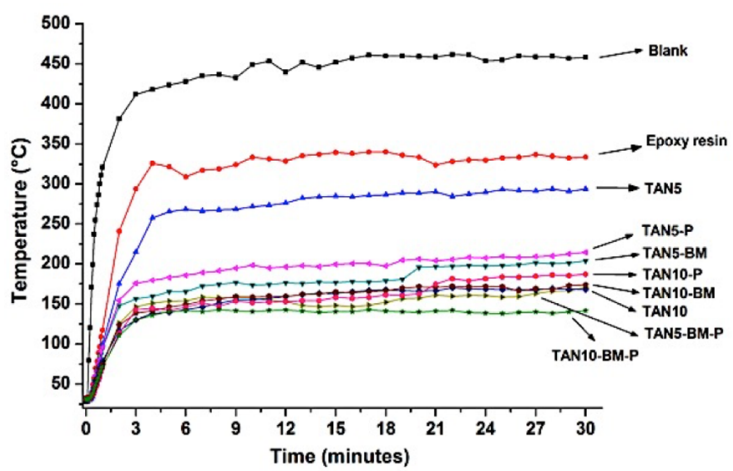

Figure 2. Temperature monitoring over time for different paint formulations.

also improves flame resistance because it acts as a charring agent ${ }^{36}$. As can be seen in Figure 2, the TAN10-BM-P coating showed the largest reduction in the temperature of the steel (maximum of $147^{\circ} \mathrm{C}$ ). The influence of black wattle tannin in fire resistance is also clear. Comparing the TAN10-BM-P and TAN5-BM-P formulations, the presence of more tannin decreased the temperature on the reverse of the steel sample. The rate of heating on the reverse can be seen by the slope of initial times (up to $60 \mathrm{~s}$ ) in Figure 2.
The slopes are as follows: $5.31^{\circ} \mathrm{C} / \mathrm{s}$ for the blank, $1.56^{\circ} \mathrm{C} / \mathrm{s}$ for epoxy resin, $1.21{ }^{\circ} \mathrm{C} / \mathrm{s}$ for TAN5, $1.22^{\circ} \mathrm{C} / \mathrm{s}$ for TAN5$\mathrm{BM}, 1.20^{\circ} \mathrm{C} / \mathrm{s}$ for TAN5-P, $0.76{ }^{\circ} \mathrm{C} / \mathrm{s}$ for TAN5-BM-P, $0.92{ }^{\circ} \mathrm{C} / \mathrm{s}$ for TAN $10,0.73{ }^{\circ} \mathrm{C} / \mathrm{s}$ for TAN10-BM, $0.73{ }^{\circ} \mathrm{C} / \mathrm{s}$ for TAN10-P and $0.69^{\circ} \mathrm{C} / \mathrm{s}$ for TAN10-BM-P. The slopes decreased sharply for TAN10-BM-P compared to the blank and the epoxy resin-coated sample.

Thermal images make it possible to observe the temperature distribution on the reverse surface and the heat affected zone of all samples (Figure 3). The highest temperatures were observed for the blank (Figure 3a) and the sample coated with epoxy resin (Figure 3b). The blank had the largest area affected by heat among all samples and had a maximum temperature of $557^{\circ} \mathrm{C}$ after $30 \mathrm{~min}$ of exposure to flame. The epoxy resin sample showed slight substrate protection against the flame, with a reduction in temperature of $141^{\circ} \mathrm{C}$, corroborating the results of the fire resistance test.

The temperature distribution of the samples with 5\% (dry mass) of black wattle tannin demonstrated an increase in fire resistance (Figure 4). It is possible to observe a considerable reduction in the temperature on the reverse surface due to the protection barrier produced by the intumescent effect. The interaction between tannin, melamine and boric acid promoted the formation of a char layer that insulated the metallic substrate from the flame. The system containing DOPO showed the lowest temperature; this can be explained by the in the gas phase, which suppresses the flame combustion radicals $(\mathrm{H}$ and $\mathrm{OH})$ by a reaction with $\mathrm{P}$-containing free radicals ( $\mathrm{P}$ and $\mathrm{PO}$ ) reducing the heat of the combustion ${ }^{37}$.

The temperature on the reverse of the samples for the formulations with $10 \%$ (dry mass) of black wattle tannin are shown in Figure 5. It can be observed that the effect of the temperature was reduced to the lowest level, mainly in the middle of the substrate. The TAN10-BM-P sample reached a temperature of around $110{ }^{\circ} \mathrm{C}$ after $30 \mathrm{~min}$, confirming improved fire resistance.

The TGA emphasised the effect of each component on the intumescent system. The formulations with boric 


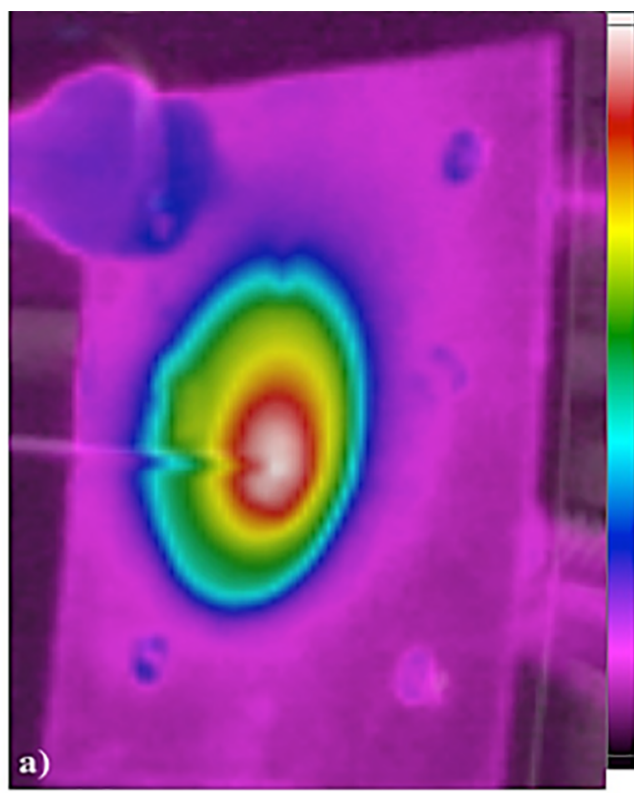

-557.2
-540
-510
-480
-450
-420
-390
-360
-330
-300
-270
-240
-210
-180
-150
-120
-90
-60
-30
13.5

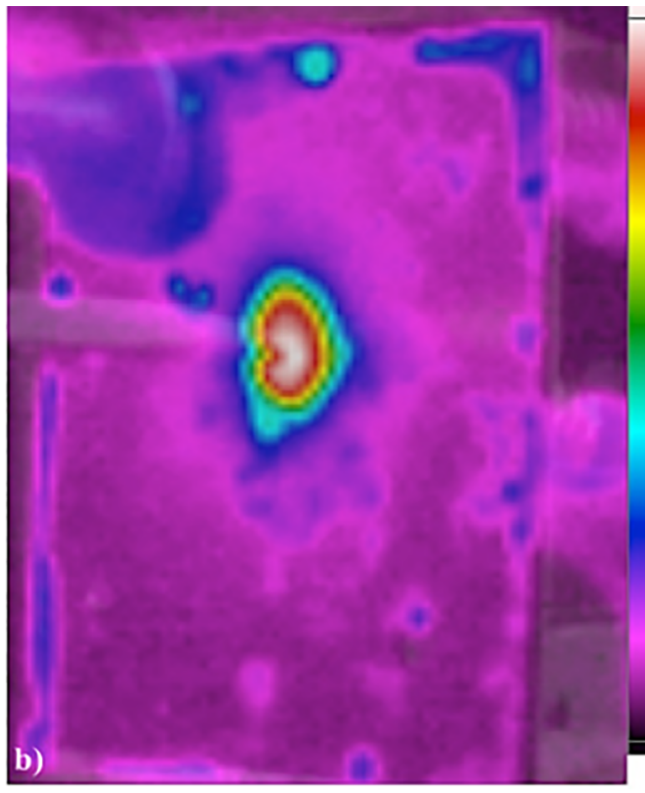

${ }^{406.2}$
-380
-360
-340
-320
-300
-280
-260
-240
-220
-200
-180
-160
-140
-120
-100
-80
-60
-40
11.9
.0

Figure 3. Temperature distribution on coated sample after $30 \mathrm{~min}$ of blowtorch application: a) blank and b) epoxy resin.
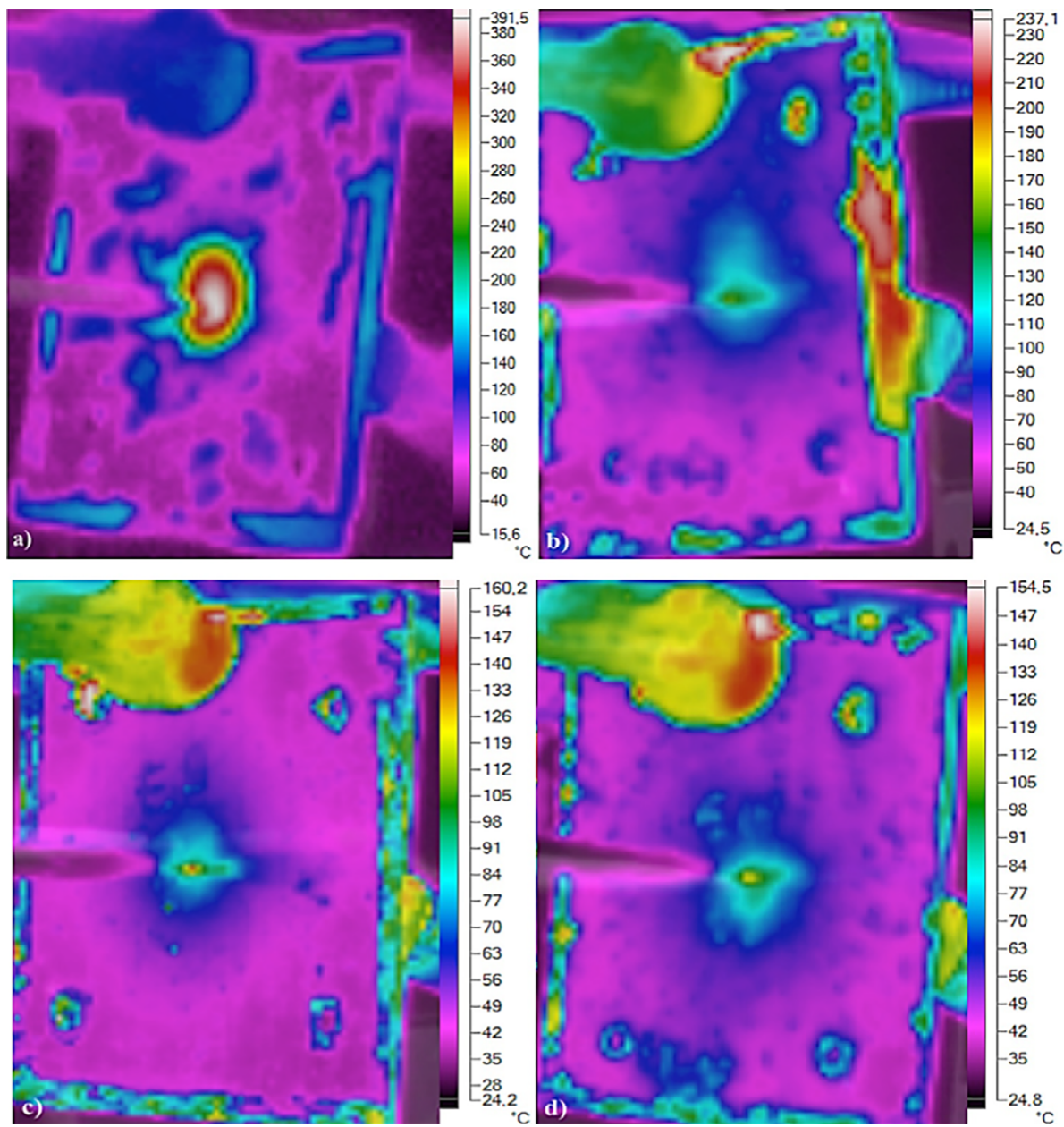

Figure 4. Temperature distribution for the TAN5 sample after $30 \mathrm{~min}$ of blowtorch application: a) TAN5, b) TAN5-BM, c) TAN5-P and d) TAN5-BM-P. 



Figure 5. Temperature distribution for TAN10 sample after $30 \mathrm{~min}$ of blowtorch application: a) TAN10, b) TAN10-BM, c) TAN10-P and d) TAN10-BM-P.

acid and melamine (TAN-BM) presented a higher amount of residue compared to the other coatings, as displayed in Figure 6 . The residue produced by the TAN10-BM sample was approximately $40 \%$ of initial weight, whereas for the epoxy resin sample the value was around $15 \%$. This result indicates that the degradation of the tannin was incomplete and this behaviour provided a charred layer formation. This phenomenon was expected due to the presence of polyphenolic molecules, which are an effective carbon source ${ }^{38}$.

The first derivatives of the weight loss curves demonstrate that the intumescent samples (TAN-BM and TAN-BM-P) showed lower degradation kinetics than the others, which is certainly due to the formation of a protective layer. The degradation of the samples with the organophosphorus compound began at lower onset temperatures of $344{ }^{\circ} \mathrm{C}$ and $342{ }^{\circ} \mathrm{C}$ for the samples TAN5-BM-P and TAN10BM-P, respectively, as can be seen in Table 2. Apparently, the phosphorus bonds for DOPO were chemically weaker than the energies of the resin bonds. In other words, there was lower activation energy for the decomposition of the material containing $\mathrm{P}^{39}$. The TAN10-BM sample showed a peak at $184{ }^{\circ} \mathrm{C}$ and $0.24 \% /{ }^{\circ} \mathrm{C}$ weight loss (Figure $6 \mathrm{~d}$ ), which indicates the dehydration of boric acid and consequently the formation of boron oxide $\left(\mathrm{B}_{2} \mathrm{O}_{3}\right)$, in line with Sevim et al. ${ }^{40}$.

The intumescent coatings containing DOPO (TAN-10BM-P) produced a lower amount of residue (32.02\%), approximately $4.35 \%$ lower than TAN10-BM. This behaviour was expected since DOPO mainly acts in the gaseous phase in providing flame retardant action. Therefore, the organophosphorus must decompose to produce active radicals, conferring flame retardant performance previously described in the studies of Schartel et al. ${ }^{41}$.

The char layer structure of the samples after the burn test is shown in Figure 7. The substrate coated with epoxy resin was unprotected during the fire test due to the immediate degradation of the epoxy resin, which made contact between the fire and steel substrate possible, highlighted in Figure 7(a). The formulations with the tannin demonstrated an increase in residue and char formation promoted by its high aromaticity, which contributed to the charring effect and prevented the 

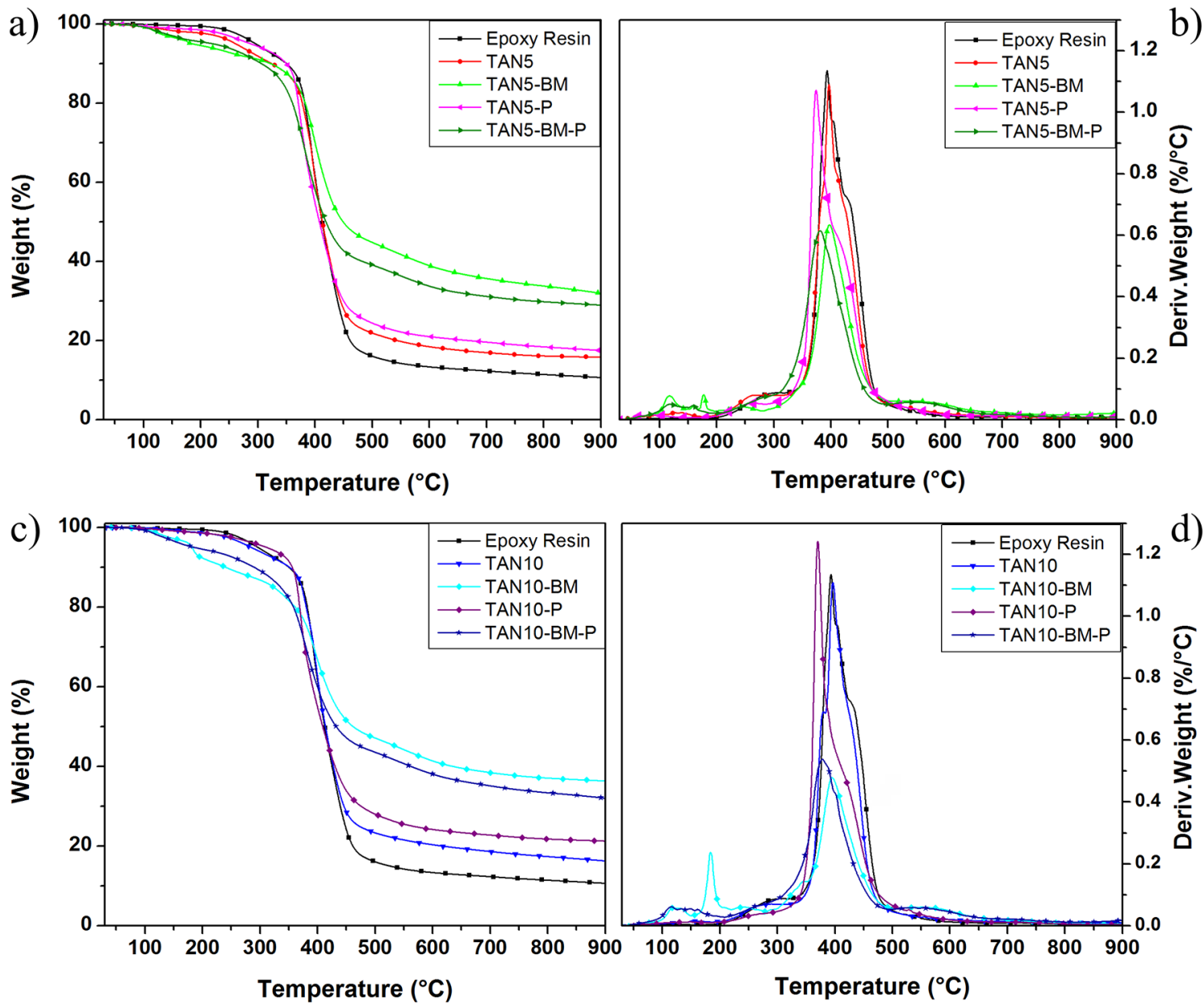

Figure 6. Thermal degradation of samples: a) TG of the TAN5 set, b) DTG of the TAN5 set, c) TG of the TAN10 set and d) DTG of the TAN10 set.

Table 2. TG and DTG Data of intumescent systems under N2 atmosphere.

\begin{tabular}{lccccc}
\hline & \multicolumn{3}{c}{ TGA } \\
\cline { 2 - 6 } Sample & $\mathrm{T}_{\text {PEAK }}\left({ }^{\circ} \mathrm{C}\right)$ & Weight at $\mathrm{T}_{\text {PEAK }}(\%)$ & $\mathrm{T}_{\text {ONSET }}\left({ }^{\circ} \mathrm{C}\right)$ & $\begin{array}{c}\text { Weight at } 500{ }^{\circ} \mathrm{C} \\
(\%)\end{array}$ & $\begin{array}{c}\text { Residue at } 900{ }^{\circ} \mathrm{C} \\
(\%)\end{array}$ \\
\hline Epoxy Resin & 393.3 & 68.58 & 367.7 & 16.08 & 10.70 \\
TAN5 & 396.7 & 64.40 & 371.0 & 21.95 & 15.80 \\
TAN5-BM & 397.3 & 71.72 & 370.1 & 44.83 & 31.96 \\
TAN5-P & 373.8 & 76.75 & 355.4 & 24.45 & 17.52 \\
TAN5-BM-P & 381.2 & 66.86 & 344.0 & 39.13 & 28.98 \\
TAN10 & 396.4 & 66.25 & 372.8 & 23.35 & 16.31 \\
TAN10-BM & 395.0 & 69.08 & 365.8 & 47.16 & 36.37 \\
TAN10-P & 370.2 & 78.77 & 356.3 & 28.08 & 21.30 \\
TAN10-BM-P & 378.1 & 70.70 & 342.2 & 43.58 & 32.02 \\
\hline
\end{tabular}

transfer of heat to the substrate. The introduction of DOPO to the intumescent systems caused a loose structure and indicated a release of volatiles containing phosphorus. These volatiles improved the extinction of flame through the dilution of the flammable gases and the replacement of hydrogen and hydroxyl radicals by recombination of phosphorus radicals in the gas phase ${ }^{42}$.

XRD demonstrated the presence of iron oxides on the steel without intumescent coating, as shown in Figure 8. This oxidation is a typical process when steel is exposed 

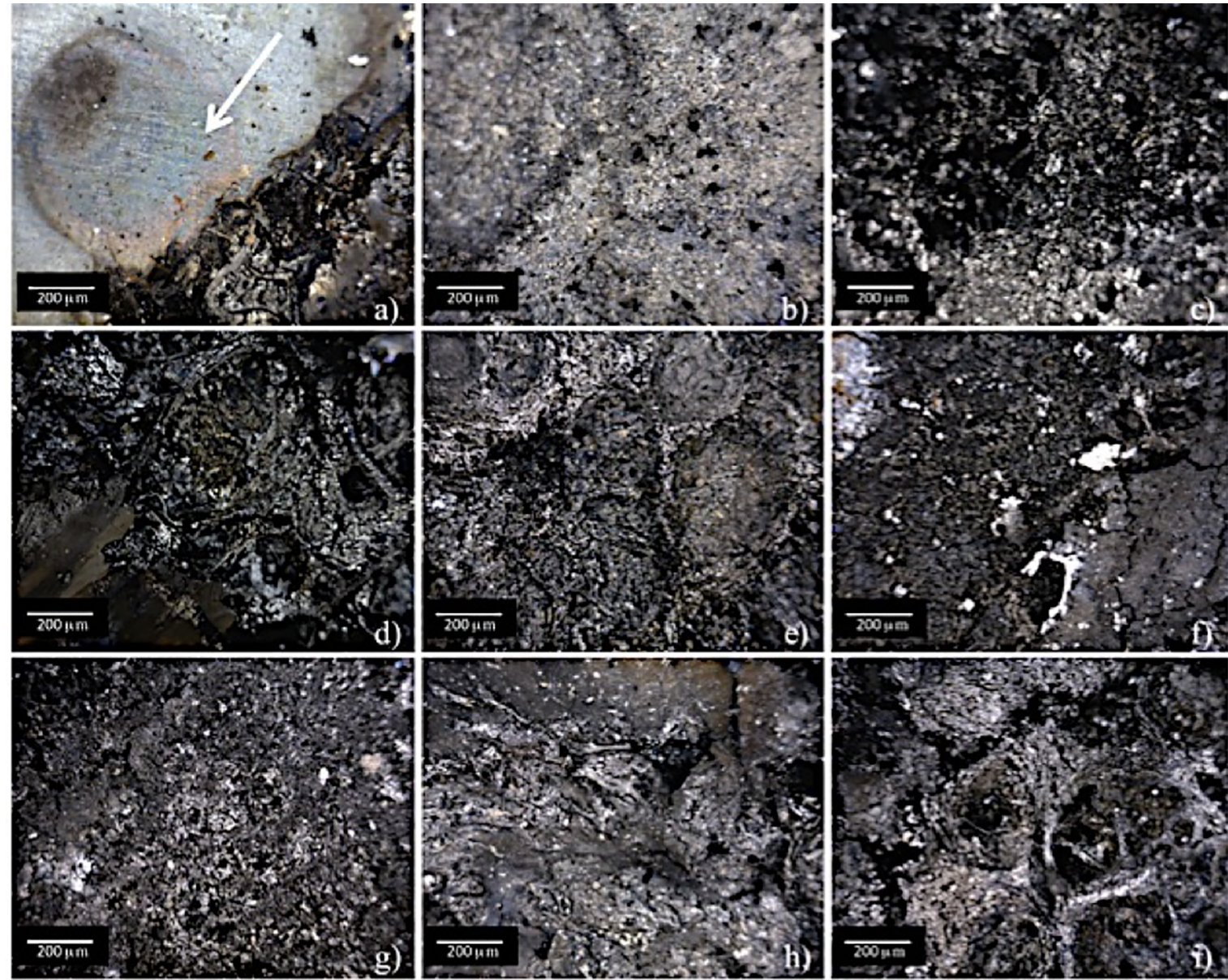

Figure 7. Optical images of the char layer after the fire test: a) epoxy resin, b) TAN5, c) TAN5-BM, d) TAN5-P, e) TAN5-BM-P, f) TAN10, g) TAN10-BM, h) TAN10-P and i) TAN10-BM-P.

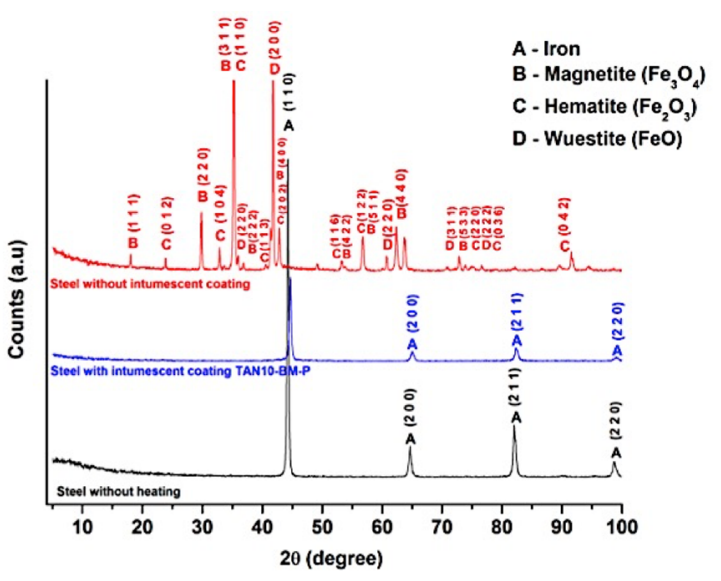

Figure 8. X-ray diffraction patterns of the steel substrates after fire test.

to high temperatures. In this case, the sample presented three iron oxides: magnetite $\left(\mathrm{Fe}_{3} \mathrm{O}_{4}\right)$, hematite $\left(\mathrm{Fe}_{2} \mathrm{O}_{3}\right)$ and wuestite $(\mathrm{FeO})$. Magnetite and hematite are the products of oxidation between $300^{\circ} \mathrm{C}$ and $600^{\circ} \mathrm{C}^{43}$. When the oxidation process occurs above $570^{\circ} \mathrm{C}$, only wuestite is formed ${ }^{44}$. The presence of wuestite on the substrate indicates that the surface has reached a temperature higher than $570{ }^{\circ} \mathrm{C}$ and this was confirmed by the thermal images. As the XRD pattern of the steel with intumescent coating TAN10-BM-P showed the same results as steel without heating, it is evident that this coating protected the substrate against fire damage.

\section{Conclusion}

The use of tannin in the intumescent coatings showed excellent results in terms of protection against fire. The thermal insulation barrier was provided by the synergistic effect of the constituents of the intumescent system. Moreover, the study demonstrated that using melamine and the organophosphorus compound as blowing agents modified the epoxy coating behaviour and changed it into an intumescent material. Furthermore, the best fire protection performance was found for the TAN10-BM-P sample, indicating that the addition of the tannin compound increased thermal insulation through the charring effect. XRD showed that the structure of the steel coated with TAN10-BM-P after the fire test was the same as the sample that had not been subjected to the fire test. Therefore, all components of the intumescent coatings had 
a specific role and the combination of their characteristics allowed the development of an efficient fireproof protective coating.

\section{Acknowledgements}

The authors gratefully acknowledge financial support from CNPq, CAPES, FAPERGS and Dow Brasil for the supply of epoxy novolac resin D.E.N 431.

\section{References}

1. Han Z, Fina A, Malucelli G. Thermal shielding performances of nano-structured intumescent coatings containing organomodified layered double hydroxides. Progress in Organic Coatings. 2015;78:504-510.

2. Nørgaard KP, Dam-Johansen K, Català P, Kiil S. Investigation of char strength and expansion properties of an intumescent coating exposed to rapid heating rates. Progress in Organic Coatings. 2013;76(12):1851-1857.

3. Wang J, Song WH, Zhang M, Chen Z. Experimental Study of the Acid Corrosion Effects on an Intumescent Coating for Steel Elements. Industrial and Engineering Chemistry Research. 2014;53(28):11249-11258.

4. Jimenez M, Bellayer S, Naik A, Bachelet P, Duquesne S, Bourbigot S. Topcoats versus Durability of an Intumescent Coating. Industrial and Engineering Chemistry Research. 2016;55(36):9625-9632.

5. Alongi J, Han Z, Bourbigot S. Intumescence: Tradition versus novelty. A comprehensive review. Progress in Polymer Science. 2015;51:28-73.

6. Duquesne S, Magnet S, Jama C, Delobel R. Intumescent paints: Fire protective coatings for metallic substrates. Surface and Coatings Technology. 2004;180-181:302-307.

7. Wladyka-Przybylak M, Kozlowski R. Thermal characteristics of different intumescent coatings. Fire and Materials. 1999;23(1):3343.

8. Bourbigot S, Le Bras M, Duquesne S, Rochery M. Recent Advances for Intumescent Polymers. Macromolecular Materials and Engineering. 2004;289:499-511.

9. Laoutid F, Bonnaud L, Alexandre M, Lopez-Cuesta JM, Dubois $P$. New prospects in flame retardant polymer materials: From fundamentals to nanocomposites. Materials Science and Engineering R: Reports. 2009;63(3):100-125.

10. Pizzi A. Tannins: Major Sources, Properties and Application. In: Belgacem M, Gandini A, eds. Monomers, Polymers and Composites from Renewable Resources. Amsterdam: Elsevier; 2008. p. 179-199.

11. Arbenz A, Avérous L. Chemical modification of tannins to elaborate aromatic biobased macromolecular architectures. Green Chemistry. 2015;17(5):2626-2646.

12. Porter LJ. Structure and Chemical Properties of the Condensed Tannins. In: Hemingway RW, Laks PE, eds. Plant Polyphenols: Synthesis, Properties, Significance. Boston: Springer; 1992. p. 245-258.
13. Mueller-Harvey I. Analysis of hydrolysable tannins. Animal Feed Science and Technology. 2001;91(1-2):3-20.

14. Zhao HJ, Liu T, Mao X, Han SX, Liang RX, Hui LQ, et al. Fructus phyllanthi tannin fraction induces apoptosis and inhibits migration and invasion of human lung squamous carcinoma cells in vitro via MAPK/MMP pathways. Acta Pharmacologica Sinica. 2015;36(6):758-768.

15. Yang Y, Xiu J, Liu J, Zhang L, Li X, Xu Y, et al. Chebulagic Acid, a Hydrolyzable Tannin, Exhibited Antiviral Activity In Vitro and In Vivo against Human Enterovirus 71. International Journal of Molecular Sciences. 2013;14(5):9618-9627.

16. Kumari M, Jain S, Dave R. Babul (Acacia nilotica): A potential source of tannin and its suitability in management of type II diabetes. Nutrition \& Food Science. 2014;44(2):119-126.

17. Belyi AV, Belaya NI, Simonova EN. The Antiradical Activity of Plant Tannins in Reactions with Electrochemically Generated Reactive Oxygen Species. Pharmaceutical Chemistry Journal. 2015;49(5):319-322.

18. Benyahya S, Aouf C, Caillol S, Boutevin B, Pascault JP, Fulcrand H. Functionalised green tea tannins as phenolic prepolymers for bio-based epoxy resins. Industrial Crops and Products. 2014;53:296-307.

19. Aouf C, Benyahya S, Esnouf A, Caillol S, Boutevin B, Fulcrand $\mathrm{H}$. Tara tannins as phenolic precursors of thermosetting epoxy resins. European Polymer Journal. 2014;55(1):186-198.

20. Hu J, Thevenon MF, Palanti S, Tondi G. Tannin-caprolactam and Tannin-PEG formulations as outdoor wood preservatives: weathering properties. Annals of Forest Science. 2017;74:18.

21. Yu Z, Shi Z, Xu H, Ma X, Tian M, Yin J. Green chemistry: Coassembly of tannin-assisted exfoliated low-defect graphene and epoxy natural rubber latex to form soft and elastic nacre-like film with good electrical conductivity. Carbon. 2017;114:649-660.

22. Pizzi A, ed. Wood Adhesives: Chemistry and Technology. New York: Marcel Dekker; 1984.

23. Peres RS, Zmozinski AV, Moreno-Martínez JA, Armelin E, Alemán $\mathrm{C}$, Ferreira $\mathrm{CA}$. Influence of $\mathrm{pH}$ in the synthesis of ferric tannate pigment for application in antifouling coatings. Journal of Coatings Technology and Research. 2017;14(4):945953.

24. Peres RS, Armelin E, Alemán C, Ferreira CA. Modified tannin extracted from black wattle tree as an environmentally friendly antifouling pigment. Industrial Crops and Products. 2015;65:506-514.

25. Qian W, Li XZ, Wu ZP, Liu YX, Fang CC, Meng W. Formulation of intumescent flame retardant coatings containing natural-based tea saponin. Journal of Agricultural and Food Chemistry. 2015;63(10):2782-2788.

26. de Souza MM, de Sá SC, Zmozinski AV, Peres RS, Ferreira CA. Biomass as the Carbon Source in Intumescent Coatings for Steel Protection against Fire. Industrial \& Engineering Chemistry Research. 2016;55(46):11961-11969.

27. de Sá SC, de Souza MM, Peres RS, Zmozinski AV, Braga RM, Melo DMA, et al. Environmentally friendly intumescent coatings formulated with vegetable compounds. Progress in Organic Coatings. 2017;113:47-59. 
28. Yang R, Ma B, Zhao H, Li J. Preparation, Thermal Degradation, and Fire Behaviors of Intumescent Flame Retardant Polypropylene with a Charring Agent Containing Pentaerythritol and Triazine. Industrial \& Engineering Chemistry Research. 2016;55(18):52985305 .

29. Yew MC, Ramli Sulong NH. Fire-resistive performance of intumescent flame-retardant coatings for steel. Materials \& Design. 2012;34:719-724.

30. Bodzay B, Bocz K, Bárkai Z, Marosi G. Influence of rheological additives on char formation and fire resistance of intumescent coatings. Polymer Degradation and Stability. 2011;96(3):355-362.

31. Ullah S, Ahmad F. Effects of zirconium silicate reinforcement on expandable graphite based intumescent fire retardant coating. Polymer Degradation and Stability. 2014;103:49-62.

32. Gardelle B, Duquesne S, Vandereecken P, Bellayer S, Bourbigot $\mathrm{S}$. Resistance to fire of intumescent silicone based coating: The role of organoclay. Progress in Organic Coatings. 2013;76(11):1633-1641.

33. Chou CS, Lin SH, Wang CI, Liu KH. A hybrid intumescent fire retardant coating from cake- and eggshell-type IFRC. Powder Technology. 2010;198(1):149-156.

34. Iji M, Kiuchi Y. Flame-retardant epoxy resin compounds containing novolac derivatives with aromatic compounds. Polymers Advanced Technologies. 2001;12(7):393-406.

35. Wang ZY, Liu Y, Wang Q. Flame retardant polyoxymethylene with aluminium hydroxide/melamine/novolac resin synergistic system. Polymer Degradation and Stability. 2010;95(6):945-954.

36. Zhong Y, Wu W, Wu R, Luo Q, Wang Z. The flame retarding mechanism of the novolac as char agent with the fire retardant containing phosphorous-nitrogen in thermoplastic poly(ether ester) elastomer system. Polymer Degradation and Stability. 2014;105:166-177.
37. Perret B, Schartel B, Stöß K, Ciesielski M, Diederichs J, Döring M, et al. A New Halogen-Free Flame Retardant Based on 9,10-Dihydro-9-oxa-10-phosphaphenanthrene-10-oxide for Epoxy Resins and their Carbon Fiber Composites for the Automotive and Aviation Industries. Macromolecular Materials and Engineering. 2011;296(1):14-30.

38. Guan YH, Liao W, Xu ZZ, Chen MJ, Huang JQ, Wang YZ. Improvement of the flame retardancy of wood-fibre/ polypropylene composites with ideal mechanical properties by a novel intumescent flame retardant system. RSC Advances. 2015;5(74):59865-59873.

39. Gao M, Yang S. A novel intumescent flame-retardant epoxy resins system. Journal of Applied Polymer Science. 2010;115(4):23462351.

40. Sevim F, Demir F, Bilen M, Okur H. Kinetic analysis of thermal decomposition of boric acid from thermogravimetric data. Korean Journal of Chemical Engineering. 2006;23(5):736-740.

41. Scharte B. Phosphorus-based Flame Retardancy MechanismsOld Hat or a Starting Point for Future Development? Materials (Basel). 2010;3(10):4710-4745.

42. Bouvet N, Linteris G, Babushok V, Takahashi F, Katta V, Krämer R. Experimental and numerical investigation of the gas-phase effectiveness of phosphorus compounds. Fire and Materials. 2016;40(5):683-696.

43. Marciuš M, Ristić M, Ivanda M, Musić S. Formation of Iron Oxides by Surface Oxidation of Iron Plate. Croatica Chemica Acta. 2012;85(1):117-124.

44. Colwell JD, Babic D. A Review of Oxidation on Steel Surfaces in the Context of Fire Investigations. SAE International Journal of Passenger Cars - Mechanical Systems. 2012;5(2):10021015. 